\section{Jornalismo em tempos de desmanche: elementos dominantes, residuais e emergentes ${ }^{1}$}

Rafael Bellan Rodrigues de Souza

\section{Resumo:}

Observando a materialidade do jornalismo em tempos de desmanche neoliberal, ascensão do capitalismo financeiro, corrosão do trabalho e plataformização da vida social, este ensaio busca compreender as contradições dessa prática humana de conhecimento. Para tanto, investiga-se, com o suporte do materialismo cultural de Williams (2011), os elementos dominantes, residuais e emergentes da práxis jornalística hoje, vista aqui no interior de processos hegemônicos de produção de consciência. O jornalismo aparece enquanto uma esfera do conjunto das formas culturais presentes no interior das práticas sociais vividas, ou seja, elemento do complexo de complexos que perfazem a cultura. Assim, com base no panorama histórico-crítico traçado, refletimos sobre a relação da práxis noticiosa com a vida cotidiana (LUKÁCS, 2013), bem como avaliamos seu potencial no enfrentamento da barbárie social e dos estranhamentos gerados pelo sistema sociometabólico do capital.

Palavras-chave: Teoria do Jornalismo. Neoliberalismo. Capital.

Journalism in times of dismantling: dominant, residual and emergent elements

\begin{abstract}
:
Observing the materiality of journalism in times of neoliberal disintegration, the rise of financial capitalism, the corrosion of work and the platformization of social life, this essay seeks to understand the contradictions of this human practice of knowledge. To this end, we investigate, with the support of Williams' cultural materialism (2011), the dominant, residual and emerging elements of journalistic praxis today, seen here within the hegemonic processes of consciousness production. Journalism appears as a sphere in the set of cultural forms that are present within the experienced social practices, that is, as an element of the complex of complexes that make up the culture. Thus, based on the outlined historical-critical panorama, we reflect on the relationship of news praxis with everyday life (LUKÁCS, 2013), as well as assessing its potential in coping with social barbarism and the strangeness generated by the sociometabolic system of capital.
\end{abstract}

Keywords: : Theory of Journalism. Neoliberalism. Capital
Recebido em: 22.11 .20

Aprovado em: 05.07.21

Rafael Bellan Rodrigues de Souza

Professor do Programa de Pós-Graduação em Comunicação e Territorialidades da Universidade Federal do Espírito Santo (Ufes). Jornalista, mestre em Comunicação pela Unesp (Bauru), doutor em Ciências Sociais pela Unesp (Araraquara) com pós-doutorado pela ECA-USP.

E-mail: rafaelbellan@ yahoo.com.br

${ }^{1}$ Uma versão preliminar deste texto foi apresentada durante o $18^{\circ}$ Encontro da Sociedade Brasileira de Pesquisadores em Jornalismo (SBPJor).

Estudos em Jornalismo e Mídia v.18, n.2, jul./dez. 2021.

ISSNe 1984-6924 


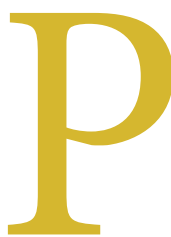

ara além de um mal estar permanente no interior das reflexões do campo do jornalismo; mais do que uma problemática profissional de um corpo de trabalhadores em cenário de desemprego contingencial; ou uma crise de credibilidade de certa estabilidade no domínio de um discurso especializado sobre a sociedade, a famigerada "crise do jornalismo" ultrapassa seus epifenômenos mais visíveis. Essa problemática não se fixa apenas na questão da viabilidade econômica da mercadoria notícia, mas se insere num conjunto de alterações sociais relacionadas, econômica e culturalmente, ao desmanche neoliberal em sua particularidade brasileira - que também pode ser entendida no interior de um continuum mais amplo da própria dinâmica incontrolável do sistema sociometabólico do capital (MÉSZÁROS, 2002) - visto como essencialmente antissocial por Antunes (2020) no contexto da pandemia de covid-19.

O capitalismo neoliberal opera no Brasil pelo desmanche (SCHWARZ, 2003) sistemático de direitos sociais e ampliação neocolonial dos níveis de subalternidade da população via corrosão do mundo do trabalho. O desencanto com horizontes transformadores e a generalização da experiência mercantil sepultam a esfera política. A hegemonia do bloco histórico dominante naturaliza a mercantilização da vida social e intensifica - no campo da cultura, das artes e da comunicação - processos de reificação, entendida com Lukács (2013) como a colonização da consciência pelos modos de produção. O sistema capitalista do século XXI via tecnologias de informação e comunicação (TICs) "deforma tanto o conhecimento e as artes que produzimos como nossos próprios sentidos" (CEVASCO, 2010, p. 138). O jornalismo como forma de conhecimento e prática social passa então por um profundo processo de contestação (CHRISTOFOLETTI, 2019). Todavia, o desafio está em investigar sua atualidade em direção diversa dos condicionantes que originaram sua convulsão: os mecanismos do metabolismo do capital em crise.

A desilusão com horizontes alternativos de vida social soma-se à glorificação do sujeito neoliberal (DARDOT; LAVAL, 2016; HARVEY, 2016), estranhado em práticas sociais estabelecidas em um cotidiano marcado por relações coisificadas que expressam um intensivo desmonte da política, do conhecimento e da cultura. O caso brasileiro é paradigmático, pois o percurso de ascensão neoliberal atravessou fases distintas, consolidando, desde o fim da perspectiva de conciliação de classes lulista, o "ovo da serpente" de um regime protofascista - cujo objetivo é estabelecer e aprofundar a contrarrevolução preventiva e permanente (FERNANDES, 1975), voltada a garantir a "servidão financeira" no território nacional.

O ultraliberalismo encontra, nas consciências estranhadas, receptáculo para associar a cultura autoritária com o falso sonho dourado das liberdades econômicas individuais. As TICs foram (e permanecem sendo) ferramentas desse projeto, ao potencializarem um ambiente em que o irracionalismo e a desinformação ganham velocidade irrestrita (SOUZA, 2020), produzindo a atomização fragmentada dos sujeitos em detrimento de processos de conscientização, os quais o jornalismo profissional alvorava ser uma de suas missões.

Este artigo visa a refletir a especificidade do jornalismo enquanto uma esfera, com autonomia relativa, do conjunto das formas culturais presentes no interior das práticas sociais vividas, ou seja, como um elemento do complexo de complexos que perfazem a cultura, atravessada pela hegemonia. A análise gramsciana ensina que a dominação da ordem social se dá pela propriedade privada dos meios de produção e pela exploração do mais-valor, mas também pela gestão dos significados, da experiência, das visões de mundo, dos hábitos, do pensar e do sentir, da totalidade das vivências que são desenvolvidas pelas classes subalternas.

Compreendendo, portanto, a direção moral e intelectual do que estamos chamando de desmanche (face brasileira neoliberal da crise estrutural do capital), há um processo vívido de mudanças, avanços e retrocessos, ou seja, uma dinâmica de elementos dominantes, residuais e emergentes (WILLIAMS, 2011) que compõem 
o mosaico do jornalismo enquanto práxis social (GENRO FILHO, 2012). Analisar essa forma de conhecimento à luz do materialismo cultural pode, não obstante, permitir cartografar as linhas gerais do estado atual do jornalismo, bem como debater seu real papel na composição da subjetividade dos sujeitos contemporâneos.

\section{Fundamentos do jornalismo e hegemonia}

O desmanche neoliberal gera abalos sísmicos notáveis na indústria jornalística. Há uma mudança pela base produtiva, com a corrosão, flexibilização e precarização do profissional de comunicação (FIGARO, 2013), que se soma à solidificação dos grandes conglomerados de internet na mediação entre os indivíduos, via redes sociais. Isso enfraquece o poder e o monopólio dos tradicionais veículos na elaboração do conteúdo jornalístico. Os novos personagens - que ganham o estatuto de produtores e consumidores de informação - defrontam-se com uma realidade em que a informação disponibilizada "gratuitamente" não exige pagamento.

Essa percepção da gratuidade e da existência de um manancial de informações inesgotáveis homogeneíza a relevância dos atores sociais, descredenciando os jornalistas. As plataformas passam a dominar o setor e dirigir a circulação dos recursos publicitários.

A reorganização da prática jornalística se dá no interior do complexo dinâmico da hegemonia, a saber, os usos do poder de classe pela via da direção moral e intelectual. A hegemonia em Williams (2011) é retratada como o conjunto sistemático e contraditório de formações sociais reais que saturam a consciência de uma sociedade. Impossível, dessa forma, tratar do jornalismo contemporâneo sem analisar o poder da internet na reorganização do modelo de comunicação e, mais do que isso, de consumo cultural.

O jornalismo passa a ocorrer tanto dentro quanto fora das empresas jornalísticas e amplia suas formas de mediação na mesma proporção em que vê sua autoridade ser colocada em xeque por conta da cristalização da "pós-verdade" como ambiente cultural do capitalismo financeiro, percepção esta construída com o auxílio dos algoritmos das redes sociotécnicas. O novo território exige novas práticas ao mesmo tempo em que ataca a expertise profissional, pois o narrar do cotidiano amplia-se a vários sujeitos, que, não qualificados, ampliam o senso comum estranhado nas redes digitais.

A imprensa tradicional, buscando reafirmar seu lugar, tenta resgatar essa autoridade por meio da prerrogativa de busca da verdade. Contudo, o contrato de comunicação e confiança, enfim, a credibilidade jornalística, também sofre a infiltração da crise de confiança na cotidianidade. As empresas jornalísticas, após décadas de submissão institucional e reafirmação da ordem hegemônica, passam a ser identificadas como parciais e comprometidas politicamente, posição que afeta correntes radicais de pensamento de transformação política e social, à esquerda e à direita.

Os fundamentos do jornalismo, como técnica de aferição da realidade fenomênica social, portador de uma estética própria de aproximação com as expressões do cotidiano e seguidora de uma ética de horizonte humanizador, são colocados em escrutínio. Todavia, longe de ameaçador, esse processo é parte da dinâmica das formas culturais e das disputas pelo sentido no bojo da luta de classes.

Filiados à matriz gramsciana de crítica marxista, Liguori e Voza (2017) apontam que o jornalismo na produção carcerária de Gramsci agrega diversas características, sendo retratado

como modalidade específica de atividade intelectual; como atividade que se remete a um importante aparelho hegemônico, decisivo para a criação do senso comum; como momento da ação do partido revolucionário, que almeja criar novo senso comum (e uma nova hegemonia), permitindo o crescimento intelectual e cultural das camadas subalter- 
nas em luta para deixarem de ser subalternas, no modelo - diversas vezes recordado - de atuação dos iluministas, que de fato prepararam, com seus escritos, a Revolução Francesa (LIGUORI; VOZA, 2017, p. 880).

Dimensiona-se a leitura do papel do jornalismo tanto na articulação do senso comum, como enquanto ferramenta da insurreição proletária. Há elementos residuais do jornalismo capazes de produzir alternativas e Gramsci dedica-se a pensar nas qualidades político-educativas de um jornal. Capturado pela dominação hegemônica, essa prática, desde o período fascista vivido pelo sardo, não poderia ser descartada pelas perspectivas transformadoras. O potencial racional crítico da prática jornalística tem eco naquilo que Moretzsohn (2007) chama de pensar contra os fatos e esclarecer os sujeitos históricos. O crescimento intelectual das massas também pode ser capturado pela lente de Genro Filho (2012), já que o conhecimento dos aspectos singulares da realidade pelo jornalismo crítico-emancipatório poderia ajudar no processo de superação dos estranhamentos (LUKÁCS, 2013). Antes, contudo, de avaliarmos o potencial dessa prática enquanto um resíduo em disputa entre o setor dominante e o alternativo, vale expor a distinção desses elementos da hegemonia, vista como "um sentido de realidade para a maioria das pessoas em uma sociedade [...]" (WILLIAMS, 2011, p. 53).

Williams (2011) vislumbra um fluxo dinâmico de composição da hegemonia. Ela é formada por disputas internas e seus antagonismos constantes e orgânicos, em que os elementos dominantes incorporam componentes residuais de formações passadas (que ainda expressem sentido social) e tentam absorver, sob sua direção, as formações emergentes (muitas vezes com potencial alternativo, ou de oposição). Sendo um exercício e uma prática, a hegemonia dimensiona as compreensões de mundo, mas só se assegura com tanto sucesso porque absorve práticas emergentes, até mesmo aquelas que poderiam ser um desafio ao complexo. O grande mérito dessa conceituação (dominante, residual e emergente) está em mapear temporalmente as formações em um bloco processual de amálgama entre o velho e o novo (residual e emergente) e as disputas de classe no bojo da cultura e das "estruturas de sentimento" (experiências e consciências) da sociedade (que podem apresentar conjuntos de visões dominantes, alternativas e de oposição). Podemos exercitar pensar o jornalismo como parte desse processo e identificar nele algumas dessas características.

\section{Elementos dominantes}

Como aparelho privado de hegemonia, o jornalismo torna-se parte profundamente relevante de disputa do projeto societário das classes no poder econômico. Ainda que, muitas vezes, o chamado jornalismo convencional das empresas de comunicação possam ter um papel de crítica a governos, o sentido predominante no conteúdo tende a reafirmar o status quo sem tocar nas efetivas estruturas de poder do sistema sociometabólico do capital. Essa prática, portanto, busca elaborar um senso comum estranhado (LUKÁCS, 2013) ao mesmo tempo em que compartilha e é produto dos "mapas de sentido" desenhados na vida cotidiana (HALL et al., 2016). Os modos de incorporação no jornalismo se dão na via da ressignificação de um discurso pautado na ideia de democracia, acoplado a uma cidadania passiva, em que essa prática se coloca como porta-voz dos interesses gerais, mas sempre no interior da institucionalidade burguesa. Ao ocultar os fundamentos econômicos e materiais e naturalizar o modo de produção capitalista, o jornalismo hegemônico torna-se uma forma de conhecimento articulado à manutenção da ordem.

Se o mundo está, presumidamente, em uma nova fase de maior inter-relação entre os mercados, qual é a (única) forma de inserção possível nesse novo contexto? A resposta, 
para este tipo de pensamento, não poderia ser mais óbvia: políticas de abertura (comercial e financeira) e desregulamentação dos mercados. Ou seja, o neoliberalismo seria a única forma de inserção possível dentro desse novo mundo globalizado (CARCANHOLO; BARUCO, 2009, p. 140).

O horizonte político de avaliação do jornalismo por grande parte dos estudiosos tende a seguir, assim, uma ideologia liberal e de compreensão ingênua acerca da concreticidade da democracia e da cidadania, ao qual ele seria um agente indispensável. Que democracia é essa da qual o jornalismo pode ser visto como fiscalizador e formador de mentalidades? Com Mészáros (2007) conhecemos a concreta diferença entre a igualdade formal e a igualdade substantiva. O jornalismo liberal apresenta como seus elementos dominantes a manutenção hegemônica da vida burguesa e do desmanche neoliberal como saída econômica para a crise civilizatória e expansão da barbárie social. Quando a pesquisa teórica e acadêmica reafirma esses valores sem aprofundá-los com o exame das engrenagens sistêmicas, ela também se enreda na articulação hegemônica. A confusão parece ser aquela direcionada pelo filósofo húngaro entre democracia e Estado, em que a ampliação da vida social e política seria sinônimo de "mais" Estado, naturalizando e invisibilizando o fato de que as instituições políticas são delimitadas pelo sistema do capital - são parte orgânica dele (CHEROBINI, 2016).

Mas se o protofascismo de um modelo ultraliberal torna-se o inimigo do jornalismo convencional, como no caso dos enfrentamentos constantes entre o bolsonarismo e a imprensa brasileira, isso mostra o quanto o próprio bloco dominante está em crise e também disputa sentidos. Todavia, o setor econômico raramente é arranhado pelo viés crítico dos jornais brasileiros, sendo que o jornalismo não consegue ter força na articulação entre os fatos sociais que eclodem no plano do singular e um contexto mais amplo de compreensão das dissonâncias sociais. Reificadas, as informações perdem seu lastro com o real histórico, incapacitando processos críticos que poderiam gerar transformações sociais.

Outro elemento dominante no jornalismo atual é o território digital que congrega a sua produção e disseminação. As regras das plataformas enquanto negócio pautado na datificação e vigilância (ZUBOFF, 2018) passaram a comandar não só o mercado de notícias, mas também a controlar o tráfego das formações alternativas (novos arranjos econômicos, jornalismo independente etc.), sendo capaz de dominar e monitorar seus efeitos em uma possível ação contra-hegemônica. A expressão do capitalismo de plataforma (SRNICEK, 2018) incide nas relações produtivas e dá suporte ao desmanche do mundo do trabalho dos jornalistas. Somado a isso, no campo ideológico, a esfera das redes torna-se maquinaria do discurso neoliberal de construção da figura do empreendedor de si mesmo. Uma sociedade neoliberal sobrevive apenas se conseguir construir dinamicamente um sujeito neoliberal. Essa visão de mundo consegue aproximar os democráticos liberais e os ultraliberais, colonizando o potencial jornalístico que poderia ser usado para o esclarecimento e a luta.

Outro fator que sustenta a dominação é a adesão do bloco histórico à decadência ideológica (LUKÁCS, 2016), expressão do abandono das formas de conhecimento pela burguesia apologética. Esse elemento dominante atua fortemente no jornalismo, enfraquecendo seu lugar nas democracias liberais ocidentais, demonstrando que a crise do capital e a miséria intelectual se aproximam (PINASSI, 2009). Como já dissemos anteriormente, as TICs ajudaram nesse processo, mas a substância da crise econômica está inegavelmente presente enquanto complexo totalizante.

Tanto o território dominante das redes (que beneficia os agentes do capitalismo financeiro) como as empresas e as organizações jornalísticas estão atravessados pelo imperativo incontrolável de acumulação capitalista. Isso não significa que essas estruturas dominantes e rígidas não sejam questionadas e forçadas a se reconfigurar. "Apesar de sua força avassaladora como porta-voz dos valores vi- 
gentes, a cultura dominante tem de conviver com elementos residuais, que vêm de outros tempos, e emergentes, que traduzem as forças da mudança" (CEVASCO, 2010, p. 141). É nessa dinâmica que podemos entender a real força do jornalismo enquanto forma social.

\section{Elementos residuais e emergentes}

Os elementos residuais são formas e sentidos permanentes na hegemonia, resgatam uma área possível do passado ainda presentificável, ou seja, "certos significados e práticas são escolhidos e enfatizados, enquanto outros significados e práticas são negligenciados e excluídos" (WILLIAMS, 2011, p. 54). Percebe-se, assim, o uso de tradições consolidadas e a manutenção de consensos efetivos funcionais à ordem, e cuja adesão social se faz ainda forte.

Agente produtor de informações absorvidas da imediaticidade dos fenômenos, o jornalismo pode ser entendido como uma prática social de produção de sentidos sobre o real histórico. O jornalismo surge como uma forma que, plasmada no cotidiano, a ele retorna, mediado por empresas e organizações lucrativas de uma sociedade de mercado. Com Genro Filho (2012) distingue-se a imprensa do jornalismo, sendo que a primeira seria o modelo industrial em que se assenta a produção noticiosa e jornalismo, mais do que essa materialidade de produção, seria a prática voltada a atender às necessidades de comunicação de uma sociedade nova, uma modalidade social de conhecimento cristalizada nos aspectos singulares da realidade. A atualidade dessa afirmação pode servir de baliza para que não seja confundida a crise da indústria de notícias, e seus mecanismos de produção, da necessidade de informação e conhecimento para os sujeitos realmente transformarem suas realidades.

Esse resíduo aparece tanto nas práticas jornalísticas convencionais quanto em outros elementos dissonantes do jornalismo convencional, como a prática de desinformação (com a emulação de notícias em formato fake news) e a mobilização de audiências no sentido de um jornalismo de propaganda comportamental (arrebatando receptores para a adesão coletiva ao projeto hegemônico das instituições). Ou seja, a necessidade de informação capaz de pautar ações sociais permanece um resíduo, mesmo em tempos de desmanche. $\mathrm{O}$ jornalismo como forma social capaz de regular a vida cotidiana dos homens e influenciar diretamente na conduta de vida dos sujeitos sociais ainda não foi expurgado.

Embora a internet tenha colocado em cena a gestão datificada da vida social e das relações comunicativas, ela potencializou contraditoriamente elementos emergentes, que dão impulso a possibilidades de novas estruturações de sentido. A criação de arranjos jornalísticos contra-hegemônicos, ou de oposição, mesmo que mantenham um pé na assimilação hegemônica, também estão com o outro pé na formação de perspectivas educativas. Veículos da internet como o Intercept, Agência Pública (de verve social-democrata), a Jacobin (revista socialista), o Esquerda Diário (rede ampla de colaboradores voltada à luta social), entre outros tantos veículos que disputam o aparelho privado de hegemonia no ambiente controlado pelas gigantes da tecnologia (Google, Facebook), demonstram a atualidade das narrativas críticas sobre a realidade social.

Emergem também na atualidade as facilidades na produção noticiosa, com o barateamento das ferramentas e as articulações com as comunidades reais e virtuais. Essas redes permitem a rápida interlocução entre agrupamentos unidos, permitindo graus variados de conversações e debates. Parece inegável que a habilitação da audiência ativa é um elemento da atualidade do território digital que pode ser uma positividade no potencial do jornalismo como cartógrafo das contradições sociais, em que se coloca o coletivo e o comum como eixo propulsor da produção noticiosa, habilitando apurações coletivas e debates públicos. 
A ferramenta do jornalismo em quadrinhos, por exemplo, tem ocupado as livrarias. Desde os importantes relatos de conflitos desenhados por Joe Sacco (2005), passando pelo relato emocionante de refugiados na França por Kate Evans (2018), até o impactante jornalismo em quadrinhos das quebradas periféricas brasileiras de Alexandre de Maio (2018). As formas estéticas de relatar o real histórico ampliam-se. Os agrupamentos de oposição precisam se atentar para a relevância em, com tipos variados de linguagens, cartografar os conflitos sociais. O suporte artístico parece apontar para uma finalidade de "representar mediante imagens sensíveis um particular que compreende em si e supera em si tanto a universalidade quanto sua singularidade (...)" (LUKÁCS, 2018, p. 195).

Mesmo que, historicamente, o jornalismo da imprensa moderna tenha se aproximado daquilo que Lukács (2018) chama de conhecimento desantropomorfizador da realidade, os movimentos alternativos de construção de um jornalismo direcionado a buscar a essência interna de conexão entre o singular e a totalidade podem se apoiar em recursos diversos (por vezes mais próximos da arte e do conhecimento antropomorfizador da realidade). A medida é o compromisso em expressar o conhecimento crítico do existente pela concreticidade de sua potência jornalística (o singular risco em mediações) (GENRO FILHO, 2012). Os riscos são tanto a estetização fetichizante do real concreto, quanto a politização agitadora que vaticina posturas sem investigar dialeticamente as engrenagens da sociedade de classes. Pontes (2015) corretamente aponta as positividades da abertura de sentido que o conhecimento jornalístico dissemina. $\mathrm{O}$ valor de uso fundamental da práxis jornalística seria essa singularidade orgânica que coloca em movimento a compreensão dos sujeitos sociais.

A imprensa alternativa e sua linguagem por vezes panfletária e "opinativa" foi por muito tempo vista como inferior ao jornalismo profissional e suas regras de expressão referencial objetiva (em sentido positivista). De fato, na linhagem de Genro Filho (2012), a especificidade de um bom jornalismo necessita ampliar seu compromisso com a desreificação, indo sempre além dos fatos sociais empiricamente perceptíveis e direcionando-se na elaboração de fatos jornalísticos que expressem a feição inovadora do singular, "como realidade que está se desenrolando, se autoproduzindo e que não apresenta um sentido fechado e nitidamente delimitado. Tal como vai germinando a árvore verde da vida" (GENRO FILHO, 2012, p. 232).

Com a corrosão do jornalismo enquanto prática estável e segura afiançada na credibilidade, os atores dessas novas formas de reportagem que rompem o cotidiano necessitam (para se fazerem relevantes enquanto conhecimento) formar e despertar o próprio público para seus produtos. A noção de jornalismo integral de Gramsci parece bastante atual, para além do contexto de fechamento histórico capitaneado pelo fascismo de ontem e de hoje. Para o filósofo do cárcere, o jornalismo integral é aquele "que não somente pretende satisfazer todas as necessidades (de uma certa categoria) de seu público, mas pretende também criar e desenvolver estas necessidades e, consequentemente, em certo sentido, gerar seu público e ampliar progressivamente sua área" (GRAMSCI, 2000, p. 197).

Com a emergente facilidade produtiva, do abundante acesso a dados e de inúmeras linguagens disponíveis, somadas à residual necessidade histórica de conhecimento dos aspectos singulares do real histórico material, amplia-se a potência desse jornalismo integral. Ele se coloca como saída aos estranhamentos multiplicados na vida cotidiana e, como forma crítica, precisa ser urgentemente acionado contra o desmanche neoliberal.

\section{Considerações finais}

Ao pensarmos o jornalismo como uma forma social de conhecimento e prática cultural que compõe um processo hegemônico, buscamos - ainda que bre- 
vemente no limite de um ensaio teórico - um mapeamento de sua relação com o desmanche neoliberal, apoiado na cultura da servidão e da expansão do protofascismo. Percebemos que o território digital organiza de forma dominante tanto a decomposição do relevo social do jornalismo, como a articulação de quem sobrevive nessa cena (as movimentações da imprensa tradicional colocam sobrevida para o jornalismo defensor da ordem econômica).

Ao despertar e incentivar uma nova configuração de relações sociais monitoradas e mercantilizadas, o bloco histórico dominante reescalona o irracionalismo e implode o jornalismo no caos informativo. Mas a dissolvição e transmutação do jornalismo tradicional também coloca novos desafios para essa prática social de conhecimento, pois um de seus elementos residuais é a indispensável leitura do real histórico conjuntural.

A hegemonia na vida cotidiana contraditoriamente habilita o sujeito como um ser comunicante, mas a contrapartida é o descompasso entre as potencialidades positivas de uma tecnologia em rede e a negatividade da exploração do capital nessa esfera. Os estranhamentos se potencializam nas mentalidades e práticas e o horizonte de barbárie social total já é avistado. Em tempos de crise estrutural do capital (MÉSZÁROS, 2002) torna-se indispensável a mobilização de recursos subjetivos capazes de, partindo do cotidiano, oferecer novos sentidos sobre o mundo social.

\footnotetext{
O fator subjetivo da história consegue desenvolver todo o seu potencial para o enfrentamento e a resolução dos conflitos só quando, por um lado, a insatisfação meramente imediata com as condições sociais dadas, a oposição contra elas, chega também teoricamente à negação da sua totalidade e quando, por outro lado, a fundamentação daí resultante, não permanece só como mera crítica da totalidade do existente, mas também se torna capaz de converter em práxis as concepções assim obtidas, ou seja, de elevar a noção teórica à condição de práxis eficaz de ideologia (LUKÁCS, 2013, p. 523).
}

O trabalho educativo e formativo de uma ação contra-hegemônica necessária é complexo e precisa ser articulado e desenvolvido em fases: "deve haver dedução e indução combinadas, a lógica formal e a dialética, identificação e distinção, demonstração positiva e destruição do velho. Mas não de modo abstrato, e sim concreto, com base no real e na experiência efetiva" (GRAMSCI, 2000, p. 206). A operação de superação de estranhamentos não se trata de uma operação mental, mas ganha mobilidade nos pores teleológicos dos sujeitos sociais, no exercício de mudanças materiais direcionadas em sua práxis. O jornalismo integral de Gramsci parece trazer novas possibilidades para situar os elementos residuais e emergentes do fenômeno da práxis noticiosa em formações culturais opositoras (que disputam por dentro da hegemonia) e alternativas (construção de nova direção moral e intelectual). Mesmo com a fragilidade do campo profissional, nosso exame aponta para elementos civilizatórios relevantes para composição de uma vida social digna.

Longe de uma idealização do jornalismo como esteio de uma democracia também fictícia, o movimento dessa prática em tempos de desmanche revela um cenário de novas articulações, capitulações, avanços e retrocessos. As rupturas necessárias à mudança das visões de mundo políticas e de uma consciência de classe necessária são passos indispensáveis e dependem de sujeitos capazes de serem mediadores qualificados para isso. A formação intelectual e militante dos jornalistas que, mais do que profissionais, são ativistas contra o desmanche, também precisa ser parte do programa de uma nova hegemonia. O conhecimento proporcionado pela práxis noticiosa é parte do imperativo de criação de um novo modo de vida. O jornalismo do futuro será o que fizermos dele. 


\section{Referências}

ANTUNES, R. Coronavírus: o trabalho sob fogo cruzado. São Paulo: Boitempo, 2020.

CARCANHOLO, M.; BARUCO, G. Pós-modernismo e neoliberalismo: duas facetas ideológico-políticas de uma pretensa nova era. Revista Lutas Sociais, PUC, n. 2, ed. 22, 2009.

CEVASCO, M. E. A cultura da servidão financeira: uma leitura às avessas. In: OLIVEIRA, F.; BRAGA, R.; RIZEK, C. Hegemonia às avessas. São Paulo: Boitempo, 2010.

CHEROBINI, D. A crítica do Estado no pensamento de István Mészáros: notas para uma aproximação. Revista Margem Esquerda, n. 26, $1^{\circ}$ sem, 2016.

CHRISTOFOLETTI, R. A crise do jornalismo tem solução? Barueri, SP: Estação das Letras e Cores, 2019.

DARDOT, P.; LAVAL, C. A nova razão do mundo: ensaio sobre a sociedade neoliberal. São Paulo: Editora Boitempo, 2016.

EVANS, K. Refugiados: a última fronteira. Rio de Janeiro: Darkside Books, 2018.

FERNANDES, F. A Revolução Burguesa no Brasil. Ensaio de interpretação sociológica. 2 ed. Rio de Janeiro: Zahar, 1975.

FIGARO, R. (Org.). As mudanças no mundo do trabalho do jornalista. São Paulo: Atlas, 2013.

GENRO FILHO, A. O segredo da pirâmide: para uma teoria marxista do jornalismo. Florianópolis: Insular, 2012.

GRAMSCI, A. Cadernos do cárcere. v. 2. Rio de Janeiro: Civilização Brasileira, 2000.

HALL, S.; JEFFERSON, T.; CLARKE, J.; ROBERTS, B.. A produção social das notícias: o mugging nos media. In: TRAQUINA, N. (Org.). Jornalismo: questões, teorias e "estórias". Florianópolis: Editora Insular, 2016.

HARVEY, D. 17 contradições e o fim do capitalismo. São Paulo: Boitempo Editorial, 2016.

LIGUORI, G.; VOZA, P. (Orgs.) Dicionário gramsciano (1926-1937). São Paulo: Boitempo, 2017.

LUKÁCS, G. Introdução a uma estética marxista. São Paulo: Instituto Lukács, 2018 .

LUKÁCS, G. Marx e Engels como historiadores da literatura. São Paulo: Boitempo, 2016.

LUKÁCS, G. Para uma ontologia do ser social II. São Paulo: Boitempo Editorial, 2013. 
MAIO, A. de. Raul. São Paulo: Elefante, 2018.

MÉSZÁROS, I. O desafio e o fardo do tempo histórico. São Paulo: Boitempo Editorial, 2007.

MÉSZÁROS, I. Para além do capital. São Paulo: Boitempo Editorial, 2002.

MORETZSOHN, S. Pensando contra os fatos: jornalismo e cotidiano: do senso comum ao senso crítico. Rio de Janeiro: Revan, 2007.

PINASSI, M. O. Da miséria ideológica à crise do capital. São Paulo: Boitempo Editorial, 2009.

PONTES, F. Adelmo Genro Filho e a Teoria do Jornalismo. Florianópolis: Insular, 2015.

SACCO, J. Uma história de Sarajevo. São Paulo: Conrad, 2005.

SCHWARZ, R. Prefácio com perguntas. In: Crítica à razão dualista/O Ornitorrinco. São Paulo: Boitempo Editorial, 2003.

SOUZA, R. B. R. A comunicação contra-hegemônica no capitalismo digital: limites e contradições. Liinc em Revista, Rio de Janeiro, v.16, n.1, maio 2020.

SRNICEK, N. Capitalismo de plataformas. Buenos Aires: Caja Negra, 2018.

WILLIAMS, R. Cultura e Materialismo. São Paulo: Editora Unesp, 2011.

ZUBOFF, S. Big Other: capitalismo de vigilância e perspectivas para uma civilização de informação. In: BRUNO, F.; CARDOSO, B.; KANASHIRO, M.; GUILHON, L.; MELGAÇO, L. (orgs.) Tecnopolíticas da vigilância: Perspectivas da margem. São Paulo: Boitempo, 2018. 